\title{
Does competency-based education with blockchain signal a new mission for universities?
}

\author{
Dr Peter Williams, University of Hull, UK
}

\section{Abstract}

New technologies and the knowledge economy are destabilising graduate professions, with artificial intelligence and the analysis of 'big data' making significant impacts on formerly-secure jobs. Blockchain technology, offering automated secure credentialling of undergraduate students' activities and achievements, may significantly erode existing systems of assessment. The challenge for universities will be not only to maintain the relevance of their curricula but also to manage erosion of their current near-monopoly in awarding degrees. This paper envisions a landscape in which universities must outsource parts of their course delivery and assessment in order to remain competitive. It examines a potentially sustainable mission strategy: to move away from narrow academic disciplines towards an authentic learning curriculum focusing on the development of students as whole persons with rounded educations. This paper examines implications for the academy of the convergence of artificial intelligence, data analytics and blockchain technology.

Keywords: learning analytics; artificial intelligence; mission strategy; soft skills; authentic assessment

\section{Introduction}

The convergence of three emerging technologies is likely to force radical change on higher education. The first is learning analytics, which over the last ten years has become increasingly important in the course delivery and management of many universities. The ready availability of vast datasets of students' online activities enables the profiling of student success behaviours and the opportunity for early intervention for failing students. However, its potential for covert data harvesting makes it ethically sensitive and controversial, as recent events in the political 
sphere have shown. The second technology-artificial intelligence (Al) - is much older, but the arrival of vast datasets on which to train machine learning systems has transformed its power to rival human experts in making judgements in complex situations. The third technologyblockchain - is newer but potentially as disruptive, promising diverse applications including the independent, secure credentialling of a range of students' educational and occupational activities and achievements.

Employed together, these three technologies present a significant challenge to the current paradigm of the relatively autonomous, degree-awarding university. Formal assessment would increasingly employ Al with learning analytics to identify credit-bearing activities and blockchain to provide tamper-proof credentialling: in portfolios owned by the student not the institution. This would be automated and independent, arising from activities and achievements both within and separate from university courses. As the acquisition of qualifications became more decoupled from the academy, universities would lose the near-monopoly they currently enjoy over degree awards and would need to reinvent themselves as degree-level educators in a broader sense. A possible reorientation towards nurturing soft skills and developing students as whole persons would have profound implications for the academy.

This paper makes an original and timely contribution to literature in higher education by envisioning how a convergence of these three technologies might force radical changes. The paper begins by outlining the changing nature of graduate professions and discusses possible impacts of developments in knowledge-intensive working and AI. Secondly, it examines learning analytics and blockchain technologies to evaluate their potential for automating the secure credentialling of students' activities and achievements. Finally, it explores potential impacts on institutions as universities seek to become more adaptive and sustainable for the $21^{\text {st }}$ century.

\section{The changing nature of graduate professions}

\section{Context}

In existing curriculum models universities typically locate degree courses within academic disciplines at the core of their missions. This organisation is reflected in university structures, almost always divided into faculties and departments composed of cognate disciplines. Such an 
operating strategy was appropriate at a time when the possession of codified academic knowledge was a key professional asset for graduates. Indeed, Bernstein (1971) saw the more vocationally-oriented degree courses as beginning a process of initiation into established professions with characteristic belief systems and strictly delimited boundaries (Macdonald, 1995). At a time when knowledge was relatively static, the academic content of a university degree might remain valid for decades. This concentration on the acquisition of propositional or Mode 1 knowledge (Schön, 1983; Gibbons et al., 1994) contrasts with what Bernstein (1996) later called 'trainability' - a preparedness for flexibility in new situations - and can be related to procedural or Mode 2 knowledge (Schön, 1983; Gibbons et al., 1994). A combination of factors including the rise of the knowledge-intensive services sector (Gotsch \& Hipp, 2012), the shrinking half-life of knowledge and rapid growth of 'frontier knowledge' (Arbesman, 2012) are shifting the ways of working and demands of the graduate professions, as will now be examined in more detail.

\section{Emerging graduate roles}

Graduate professionals in the $20^{\text {th }}$ century enjoyed relatively long career paths in occupations where their academic knowledge was a prime asset. The $21^{\text {st }}$ century has seen shortening knowledge life-cycles (Chen et al., 2010) and a trend from stable jobs with single employers towards a 'gig economy' (Manyika et al., 2016) of multiple careers and short-term project-specific employment (Bersin, 2017). Thomas \& Seely Brown, (2011) argue that the previous reliance on propositional knowledge curated by academic experts is being displaced by rapidly growing procedural knowledge created by practitioners. These major changes call for a reappraisal of traditional university curricula: from a 'front loaded' 3-4 year delivery model of 'just-in-case' learning towards a flexible, lifelong model of 'just-in-time learning' (Stavredes, 2005). Seely Brown (2012) calls this scalable learning, emphasising the heterogeneous development of procedural knowledge through networks and, as will be discussed later, the 'badging' accreditation of learning by experience in work-based environments.

\section{Emerging technologies}

The convergence of relatively recent ICT developments including 'big data' (the analysis of massive datasets) with the more established technology of $\mathrm{Al}$ is greatly extending the power of computers to make complex judgements. Kahneman (2011) distinguishes between what he calls 
System 1 and System 2 thinking, with the former akin to intuitive leaps and the latter slower, more conscious and deliberate. Computers are well suited to System 2 tasks employing algorithmic processes, but Al systems have until recently been less successful in making nuanced judgements. McAfee \& Brynjolfsson (2017) argue this shortcoming has been transformed by the coupling of Al with big data, citing several examples from business, academia, medicine, education and law, where experienced human experts can now only at best equal computers in devising solutions to complex problems.

\section{Impacts on graduate roles}

Several commentators predict significant impacts of artificial intelligence on the future roles of graduate professionals. Al is already affecting the legal profession, and although Remus \& Levy (2016) guard against a simplistic view of 'robots replacing lawyers' - pointing out that only relatively structured and repetitive tasks are readily subject to automation - they do acknowledge that this raises broader questions as to the training of lawyers and the possible effects of Al on the law itself. Sherman (2015) is bolder, citing the following professions as under threat from Al developments: financial and sports reporters; online marketers; anaesthiologists, surgeons and diagnosticians; e-discovery lawyers and law firm associates; and financial analysts and advisors. A detailed mathematical model devised by Frey and Osborne (2017) ranks the likelihood of computerisation in over 700 occupations. These range from, at the low-probability end, therapists and social workers, to the at-risk occupations identified by Sherman (2015) including - with a probability of 0.94 - accountants and auditors. The McKinsey Global Institute estimates that by 2030,800 million jobs globally might be displaced by $\mathrm{Al}$, but stress that new ones will also result (Manyika, 2017). Al will create as well as destroy, and in this Schumpeterian view (Schumpeter, 1994), new professional occupations can be identified. For example, the University of Sydney (2017) describes the following "6 jobs you've probably never heard of" as: urban agriculturalist, micro fabricator, synthetic systems biologist, biomedical engineer, spatial micro performance designer, and creative technologist.

Changing roles and opportunities suggest the need for different skill sets and learning dispositions, and this has been the focus of recent research. An extensive survey of occupational skills literature conducted by Voogt \& Roblin (2010) found collaboration, communication and social/cultural competencies to be common to all the sources reviewed, with critical thinking, problem solving and creativity also important. Lai \& Viering (2012) list what they call 21st century 
skills as: critical thinking, creativity, collaboration, metacognition and motivation. Williams (2016) compares the competencies and dispositions evident in knowledge working literature with those of employers' preferences, exhibiting a high level of concordance for communication, collaboration, initiative and adaptability. In a major project relating theoretical and empirical enquiry, the Crick Learning for Resilient Agency Survey (CLARA, 2016) identifies eight dimensions of learning power as being: mindful agency, sensemaking, creativity, curiosity, belonging, collaboration, hope and optimism, and orientation to learning. Personal and social dispositions are prominent in all of these taxonomies, and McAfee and Brynjolfsson (2017) see the development of social skills in emerging occupations as becoming of comparable importance to those of quantitative analysis. Clearly, the ability to operate effectively as team players fits well with the emerging graduate roles discussed earlier.

Both the threats to existing occupations and the emergence of new ones compounds the imperative for universities to be swiftly adaptive in order to maintain their commanding position over induction into professional careers. The remainder of this paper will argue that piecemeal changes will be insufficient to stem this tide and that what is needed is a major reorientation to inform radical solutions.

\section{Potential impacts of emerging technologies on assessment}

A focus on assessment has been taken in this paper to reflect its importance as both a driver and obstacle to change in an outcomes-based approach to curriculum that centres on the student (Tam, 2014). Williams (2014a) examines three dimensions of assessment, the most important of which for present discussion are granularity and epistemology. Granularity is defined as the frequency and scheduling of assessment points throughout the learning process, and epistemology as a view of the types of knowledge - propositional or procedural - underpinning assessment. The assumptions typifying conventional university assessment are contrasted with those associated with the authentic assessment of knowledge embedded in realistic contexts (Gulikers et al., 2004; Ashford-Rowe et al., 2013) that is acquired experientially through authentic learning. Redecker \& Johannessen (2013) draw a distinction between what they call the Explicit Testing Paradigm and the Embedded Assessment Paradigm. In the former, ICT is used to improve the efficiency and effectiveness of testing learners' retention of knowledge; this supports the traditional purpose of testing as an event set apart from the process of learning. In the latter, ICT 
enables assessment to be embedded in the learning process in order to capture complex skills and competencies that would be difficult to assess by other means; assessment would therefore become contemporaneous with and integral to learning. It is the contention of this paper that a shift in emphasis away from: the infrequent, often norm-referenced, summative assessment of propositional knowledge that typifies conventional university practice; towards the more finelygrained, often criterion-referenced, formative assessment of knowledge-in-action (Greiner, discussed in Poulfelt \& Buono 2017); is an approach more appropriate to the needs of $21^{\text {st }}$ century undergraduate students. For a variety of practical reasons, this latter approach has proved difficult to implement, but emerging technologies have the potential to alter that balance.

\section{Learning analytics and Al}

Learning analytics has been defined as 'the measurement, collection, analysis and reporting of data about learners and their contexts, for purposes of understanding and optimizing learning and the environments in which it occurs' (Long \& Siemens 2011, 34). The data are drawn from students' online activities, enacted typically in virtual learning environments (learning management systems). Educational data mining techniques (Scheuer \& McLaren, 2012) reveal semantically meaningful patterns in these very large datasets to create probabilistic, predictive models known as student success algorithms (Arnold \& Pistilli, 2012). The first uses of learning analytics were to inform tutor interventions for students who might be at risk of failing. The OU Analyse system at the UK Open University is an example of this predictive analytics, employing machine learning techniques to provide weekly early warning indicators of students' progress (OUA, 2018), and Herodotu et al. (2017) describe a large-scale study investigating the diverse ways in which Open University teachers employed OU Analyse for their distance education students.

Concerns have grown about the ethical integrity of this way of using learning analytics. Slade \& Prinsloo (2013) argue for openness with students on how and for what purposes their data will be harvested; Pardo \& Siemens (2014) have similar concerns, propounding a set of principles comprising: transparency, student control over data, right of access, and accountability. There are other applications for learning analytics, however, that prioritise the needs of students over those of institutions; these emphasise the provision of formative assessment and the analysis of students' engagements in wider activities beyond the classroom. 
Learners' dispositions are a key factor in social learning analytics. This focus developed from the first-generation model and, like assessment for learning, examines students' experience, both individually and when engaged in collaborative learning. Buckingham Shum \& Deakin Crick (2012) describe this complex field as embracing five components: learners' collaborative networking; discourse analysis of textual exchanges; learner-generated content, for example through collaborative bookmarking; disposition analytics, exploring learners' intrinsic motivations; and context analytics concerning the range of contexts and locations in which learning takes place. In their later paper, Buckingham Shum \& Deakin Crick (2016) attempt to relate these five components to $21^{\text {st }}$ century competencies, acknowledging that social learning analytics is at an early stage of development.

The management orientation of the first generation of learning analytics can be contrasted with the second, in what might be called an assessment for learning orientation - the provision of formative assessment - in which detected patterns of academic behaviour are made available to the students. The employment of feedback in this way formed part of a large-scale empirical study conducted by Tempelaar et al. (2015), who collected data from a blended learning course in which 922 students were presented with feedback from tests, quizzes and mastery environments. The learning dispositions of the students were assessed using an analytics framework devised by Buckingham Shum \& Deakin Crick (2012), finding that the best prediction of final outcomes was a combination of dispositional and performance data.

The take-up of learning analytics by universities continues to grow, particularly in the USA, UK and Australia (Jisc, 2017), and international dissemination of research in the topic is burgeoning (SoLAR, 2018; Jisc, 2018a). It is likely that advances in Al machine learning, operating on the vast amounts of data now available on students' online learning activities, will further speed the progress of these initiatives.

\section{Competency-Based Education 'powered by blockchain'}

Competency-Based Education (CBE) is not a new approach but, supported by ICT has recently experienced rapid growth. CBE emphasises the mastery by students of explicit and transferable learning objectives in a learning environment that provides timely and personalised support and formative feedback, with the aim being for students to develop and apply a broad set of skills and 
dispositions to foster critical-thinking, problem-solving, communication and collaboration (Sturgis, 2016). There are several examples of university involvement in CBE initiatives. An early implementer was Western Governors University in the USA, which claims to be the only university offering competency-based degrees at scale (WGU, 2018). Thirty colleges and universities in the USA are members of the Competency-Based Education Network formed in 2014, which provides a resource library of reports and toolkits (C-BEN, 2018). The University Learning Store (2018), which is a partnership of six US universities, operates a similar model, with courses including Communicating \& Deliberating in Work Teams, and Presenting Effectively to Global Audiences. These examples are all proprietary, owned and controlled by institutions and consortia. The implications of automated systems of credentialling will now be discussed: these are 'powered by blockchain'.

Blockchain has been described as a secure online Mutual Distributed Ledger providing 'an electronic public transaction record of integrity without central ownership' (Mainelli \& Smith, $2015,3)$. It is associated with cryptocurrencies (Grinberg, 2012) but has several other applications including secure systems for warranting students' educational achievements. A more detailed technical description is provided by Watters (2016):

The blockchain is a distributed database that provides an unalterable, (semi-)public record of digital transactions. Each block aggregates a timestamped batch of transactions to be included in the ledger - or rather, in the blockchain. Each block is identified by a cryptographic signature. These blocks are all back-linked; that is, they refer to the signature of the previous block in the chain, and that chain can be traced all the way back to the very first block created. As such, the blockchain contains an un-editable record of all the transactions made.

In addition to secure storage, blockchain also provides smart contracts: computer programs controlling the transfer of assets between parties. Like conventional contracts, they define rules of agreement, but are 'smart' in that they are automatically processed when presented with the necessary data. This enables trusted transactions and agreements to be actioned without the need for mediation or a central authority, and in a way that makes them traceable, secure and irreversible. For this technology to be applied to the secure certification of educational achievement, agreed and binding standards are needed, and a number of initiatives are in progress. The first, Blockcerts (2018), was developed at the Massachusetts Institute of 
Technology by MIT Media Lab and the Learning Machine company (2017) as an open standard for creating smart contract apps and comprises open-source libraries and tools. Where Blockcerts defines the protocol, Learning Machine supplies a commercial product based on these standards, with example certificates of academic accomplishment. MIT has introduced Digital Diplomas, employing Blockcerts and available via a smartphone app enabling graduates to share a tamperproof digital version of their certificates with prospective employers (Durant \& Trachy, 2017). Another application has been developed by Sony Global Education, which is undertaking the maintenance of "Next Generation of School ICT Environment" for the Ministry of Internal Affairs and Communications in Japan (SGE, 2017). Several universities have started to offer courses about blockchain (Arnold, 2017), but in March 2018 plans were announced for what is claimed to be the world's first blockchain-powered university. Woolf University (2018) was formed by a small group of Humanities academics at Oxford University. It aims to be an online university based around an app that allows academics to advertise their expertise and students to choose modules as credits towards undergraduate degrees. Fees would be paid in a cryptocurrency called Woolf Tokens (Broggi et al. 2018). Blockchain smart contracts will record module attendance, regulate payments and record academic achievement and delivery will be modelled on the Oxford individual tutorial, via video conferencing such as Skype. Hence, Woolf will be educationally traditional but radically different in management; where existing universities employ teams of managers and system administrators to mediate between students and their teachers, it is claimed the use of blockchain for Woolf will result in lower course fees for students and higher pay for its academic staff.

Research into the educational implications of blockchain is moving rapidly. The UK Open University project Openblockchain (2018) offers an excellent overview of the technology and its potential. Other research in Europe, conducted on behalf of the European Commission and reported by Grech \& Camilleri (2017), prompted the launch in February 2018 of the EU blockchain Observatory and Forum (EC, 2018a) and two months later, the inception of a blockchain Partnership of 22 EU countries (EC, 2018b) for the exchange of experience and expertise to inform the launch of EU-wide blockchain applications.

Caveats concerning this technology should be noted. Blockchain underpins Bitcoin, which has been associated with financial dealings that resembled Ponzi schemes, and there are many technical traps for the uninformed and unwary (Gerard 2018). Hamilton (2017) views blockchain as "currently at the peak of the hype cycle" and at a very early stage of development; its slow 
transaction time is a limitation, as is its reliance upon cryptocurrencies. Although in the medium term it may not prove the vehicle for secure online credentialling, in the short term it remains the most significant technology available.

Blockchain 'powered by learning analytics'

Blockchain will support many modes of use, but those presenting the most radical challenge to existing university curricula and delivery are likely to arise from the convergence of blockchain with the second generation of learning analytics. The outcome will be systems that independently and automatically provide student achievement data for processing by smart contracts, leading to secure certification that is neither initiated, owned or awarded by educational institutions. Free-standing certification systems such as Open Badges (2016) have not made inroads into higher education, and proprietary apprenticeship schemes by technology corporations such as Apple, BMW and Microsoft have operated for many years, but are limited to potential employees and involve costs of enrolment, tuition, assessment and certification. By contrast, blockchain-based systems 'powered by learning analytics' are less constrained in application and scope and could be delivered at very low cost in exchange for cryptocurrency payments.

There are three main reasons why such developments might become widespread. The first is cost. For students faced with rising tuition fees, particularly in the USA and UK, the low-cost blockchain accreditation of work-based learning achievements would be immediately attractive. The second advantage is flexibility. Unlike institution-managed accreditation governed by course and assessment timetables, that offered by, for example, Blockcerts would be accessible at times and locations to suit students. The third advantage is portability. In the view of Stensaker \& Maassen (2015) there is an increasing need in higher education for trustworthy quality assurance across international boundaries, and Li (2015) makes a similar call for credit recognition systems across Chinese universities. Blockchain-based qualifications offer such international access and currency.

The stages through which students' engagement and activities would be collected, assessed, validated and disseminated are summarised in Table 1. As can be seen, most or all of this processing could be either in-house on university-managed systems or outsourced to trusted third-party organisations. As this is a highly complex process it is unlikely that the analytics 
employed in Stage 2 would initially be as comprehensive as shown. Over time, iterative machine learning on growing datasets would drive greater validity and sophistication.

Table 1: Five stages of data processing from student activity to blockchain certification

\begin{tabular}{|l|l|}
\hline Stage 1 & $\begin{array}{l}\text { Students' online activity in on-campus tasks or work placement projects is captured } \\
\text { and stored in large datasets on university-hosted or external secure network } \\
\text { servers. }\end{array}$ \\
\hline Stage 2 & $\begin{array}{l}\text { Second generation learning analytics systems supported by Al, on either university- } \\
\text { managed or secure external platforms, are used to assess each student's level of } \\
\text { engagement in: collaborative networking; discourse analysis; learner-generated } \\
\text { content; disposition analytics, intrinsic motivations; and context analytics } \\
\text { (Buckingham Shum \& Deakin Crick, 2012). }\end{array}$ \\
\hline Stage 3 & $\begin{array}{l}\text { Analytics outcomes are matched to student success algorithms; these include the } \\
\text { validation of individual and collaborative achievements. Those meeting the defined } \\
\text { criteria of (preselected) smart contracts are prepared for transmission. }\end{array}$ \\
\hline Stage 4 & $\begin{array}{l}\text { Triggering, either automatically or manually by student / university / work } \\
\text { placement supervisor, of smart contracts and the transmission of input data to } \\
\text { blockchain ledgers. }\end{array}$ \\
\hline Stage 5 & $\begin{array}{l}\text { Certification (for example, by Blockcerts) of the students' individual and } \\
\text { collaborative achievements are made publicly available via blockchain. } \\
\text { Cryptocurrency payments are made to service providers as required. }\end{array}$ \\
\hline
\end{tabular}

\section{Potential impacts of emerging technologies on institutions}

The availability of certification services independent of university control will accelerate the existing trend for degrees or equivalent qualifications to be gained without traditional university involvement. According to the Program for Research on Private Higher Education (Levy, 2018), almost a third of higher education students globally are studying through private providers, 70 per cent of whom are in the developing world. Students from countries with less developed higher education infrastructures may find such online certification particularly welcome. The potential for secure, low-cost, globally-accessible credit accumulation and award seems considerable and likely to prompt radical changes in curricula and delivery.

\section{New curriculum content and delivery}

The personal dispositions and competencies needed for the future are amply evident in the literature reviewed earlier. To achieve greater sustainability and 'future-proofing' of curricula universities may judge it necessary to shift emphasis from academic disciplines towards procedural knowledge-in-action, nurturing soft skills and developing students as whole persons 
with rounded educations, more agile and adaptable for changing circumstances. There are interesting resonances with John Henry Newman's idea of the university as providing a liberal, cultural education for the whole person (Ker, 2011). Criteria that might be considered are Lombardi's (2007) ten design elements for an authentic learning curriculum, summarised in Table 2.

Table 2: Design elements for an authentic learning curriculum (after Lombardi, 2007)

\begin{tabular}{|l|l|}
\hline (1) & Real-world relevance: providing authentic activities within a realistic context. \\
\hline (2) & $\begin{array}{l}\text { Ill-defined problem: confronting challenges that may be open to multiple } \\
\text { interpretations. }\end{array}$ \\
\hline (3) & Sustained investigation: undertaking complex tasks over a realistic period of time. \\
\hline (4) & $\begin{array}{l}\text { Multiple sources and perspectives: employing a variety of perspectives to locate relevant } \\
\text { and useful resources. }\end{array}$ \\
\hline (5) & Collaboration: achieving success through division of labour and teamworking. \\
\hline$(6)$ & Reflection (metacognition): reflecting upon individual and team decisions. \\
\hline (7) & $\begin{array}{l}\text { Interdisciplinary perspective: encouraging the adoption of diverse roles and } \\
\text { thinking. }\end{array}$ \\
\hline (8) & $\begin{array}{l}\text { Integrated assessment: coinciding the learning process with feedback that reflects real- } \\
\text { world evaluation. }\end{array}$ \\
\hline (9) & $\begin{array}{l}\text { Polished products: accomplishing real and complete outcomes rather than completing } \\
\text { partial exercises. }\end{array}$ \\
\hline (10) & $\begin{array}{l}\text { Multiple interpretations and outcomes: appreciating diverse interpretations and } \\
\text { competing solutions. }\end{array}$ \\
\hline
\end{tabular}

Several universities are already taking steps towards an authentic learning curriculum, and two examples from Australia are reported here. According to the University of Sydney, its new undergraduate curriculum for 2018 has been designed in the recognition that graduates will change jobs several times in their careers, so broader undergraduate experiences will be needed. A new combined Bachelor of Advanced Studies enables students to tailor their degree through interdisciplinary studies, online components and engagement with projects and research in community, industry or entrepreneurship settings (University of Sydney, 2018). The University of Queensland makes similar offers of courses with opportunities for practical workplace experience including an employability award in extra-curricular activities and professional development (UQ, 2018). While both universities are actively redesigning their course offers for the future, the methods of assessment remain traditional in the sense of employing Redecker and Johannessen's (2013) Explicit Testing Paradigm, discussed earlier. The use of work placements is common in many vocationally-oriented degree courses in the health sciences, engineering and teaching, but again, the bulk of assessment lies with the academic rather than applied components of these courses, and all assessed performance is institutionally managed or validated. The use of automated accreditation systems outwith university control would enable students to gain 
professional credentials more flexibly through employment experience. However, such a decoupling of professional qualifications from academic conferment would weaken the power of universities by limiting the scope of their formal assessment and awards and forcing a reappraisal of their missions.

\section{New university missions}

How the academy might address the challenge of losing its near-monopoly on assessment is a matter of speculation, but it is likely that universities would seek to draw upon their reputation for integrity and ethical dealing. In addition to course delivery, their new role might be as 'education services advisers' - honest brokers helping their students develop graduate portfolios of educational assets drawn from and blockchain-validated by a variety of providers, as supplements to the course credits gained in-house. Prestigious universities would be well placed to quality assure credentials that would be globally available, in return for service payments via blockchain.

Such mission reappraisals would probably be incremental, shadowing adoption of the new assessment practices discussed earlier, and would likely affect some academic disciplines more than others. The pioneering practice of high-status organisations such as MIT and the University of Sydney could set an agenda likely to be followed, resulting in the universities of 2040 being significantly different to those of the present day.

\section{Conclusion}

This paper has discussed ways in which Al-supported learning analytics will continue to proliferate and there is ample evidence to underpin this view. By contrast, blockchain is much newer and although it has seen a rapid growth of interest in Europe, the USA and Japan, there is at the time of writing less available evidence as to whether its promise will be realised; caveats concerning its use have been identified earlier. The convergence of these three technologies does appear extremely possible, however, and likely to realise the far-reaching changes discussed. 
The choice facing university policymakers is how to act in the short term. To be in a position to make informed choices universities should carefully monitor the reports of specialist agencies such as the Horizon Scanning Project (Jisc, 2017; 2018b), the Observatory on Borderless Higher Education (OBHE, 2018), the EU blockchain Observatory and Forum (EC, 2018a) and the annual Horizon reports (EDUCAUSE, 2018). Pilot projects and the sharing of expertise between institutions would also be helpful at this early stage - which might be described in the words of Mao Zedong as 'letting a hundred flowers blossom'. Above all, universities must be proactive in addressing this latest challenge and in adapting their missions, structures and practices to maintain viability and sustainability for an uncertain future.

\section{References}

Arbesman, S. (2012). The Half-life of facts: why everything we know has an expiration date. New York: Penguin Group.

Arnold, K., \& Pistilli, M. (2012). Course signals at Purdue: using learning analytics to increase student success. Paper presented at the 2 nd international conference on learning analytics \& knowledge, Vancouver, Canada.

Arnold, M. (2017). Universities add blockchain to course list. Financial Times, June 18. Retrieved from: https://www.ft.com/content/f736b04e-3708-11e7-99bd-13beb0903fa3

Ashford-Rowe, K., Herrington, J. \& Brown, C. (2014). Establishing the critical elements that determine authentic assessment. Assessment \& Evaluation in Higher Education, 39, 205-222.

Bersin, J. (2017). Catch the wave: The 21st-century career. Deloitte Review, 21, 62-79.

Bernstein, B. (1971). On the classification and framing of educational knowledge. Knowledge and Control 3, 245-270.

Bernstein, B. (1996). Pedagogy, symbolic control and identity: theory, research and critique. London: Taylor and Francis.

Blockcerts. (2018). Blockcerts: the open standard for blockchain certificates. Retrieved from: https://www.blockcerts.org/guide/

Broggi, J., Lilly, J. \& Duquette, J. (2018). Woolf University token paper. Retrieved from: https://woolf.university/assets/doc/token-economics.pdf

Buckingham Shum, S. \& Deakin Crick, R. (2012). Learning dispositions and transferable competencies: pedagogy, modelling and learning analytics. Paper presented at the $2 n d$ international conference on learning analytics \& knowledge, Vancouver, Canada.

Buckingham Shum, S. \& Deakin Crick, R. (2016). Learning analytics for 21st century competencies. Journal of Learning Analytics, 3, 6-21.

C-BEN. (2018). Competency-based education network: A national consortium for designing, developing and scaling new models for student learning. Retrieved from: http://www.cbenetwork.org

Chen, A., Hwang, Y., \& Raghu, T. (2010). Knowledge life cycle, knowledge inventory, and knowledge acquisition strategies. Decision Sciences, 41, 21-47.

CLARA. (2016). The Crick learning for resilient agency survey resource website. Retrieved from: http://clara.learningemergence.com 
Durant, E. \& Trachy, A. (2017). Digital diploma debuts at MIT. MIT News, October 17. Retrieved from: http://news.mit.edu/2017/mit-debuts-secure-digital-diploma-using-bitcoin-blockchaintechnology-1017

EC. (2018a). European Commission launches the EU Blockchain Observatory and Forum. European Commission, Brussels. Retrieved from: https://ec.europa.eu/digital-singlemarket/en/news/european-commission-launches-eu-blockchain-observatory-and-forum

EC. (2018b). European countries join blockchain Partnership. European Commission, Brussels. Retrieved from: https://ec.europa.eu/digital-single-market/en/news/european-countries-joinblockchain-partnership

EDUCAUSE. (2018). NMC horizon report preview 2018. Retrieved from: https://library.educause.edu/resources/2018/4/nmc-horizon-report-preview-2018

Frey, C. \& Osborne, M. (2017). The future of employment: How susceptible are jobs to computerisation?. Technological Forecasting and Social Change, 114, 254-280.

Gerard, D. (2018). Attack of the 50 foot blockchain. Retrieved from: https://davidgerard.co.uk/blockchain/book/

Gibbons, M., Limoges, C., Nowotny, H., Scott, P., Schwartzman, S., \& Trow, M. (1994). The new production of knowledge: the dynamics of science and research in contemporary societies. London: Sage.

Gotsch, M. \& Hipp, C. (2012). Measurement of innovation activities in the knowledge-intensive services industry: a trademark approach. The Service Industries Journal, 32, 2167-2184.

Grech, A. \& Camilleri, A. (2017). Blockchain in education. Joint Research Centre Science for Policy Report, European Commission, Brussels._Retrieved from: http://publications.jrc.ec.europa.eu/repository/bitstream/JRC108255/jrc108255 blockchain i n education\%281\%29.pdf\#page $=66$

Grinberg, R. (2012). Bitcoin: an innovative alternative digital currency, Hastings Science and Technology Law Journal. HeinOnline, 159-208. Retrieved from: http://heinonline.org/HOL/LandingPage?handle=hein.journals/hascietlj4anddiv=6andid=andp age $=$

Gulikers, J., Bastiaens, T. \& Kirschner, P. (2004). A five-dimensional framework for authentic assessment. Educational Technology Research and Development, 52, 67-86.

Hamilton, M. (2017). Blockchain in research and education. Jisc Report. Retrieved from: https://www.jisc.ac.uk/reports/blockchain-in-research-and-education

Herodotou, C., Rienties, B., Boroowa, A., Zdrahal, Z., Hlosta, M, \& Naydenova, G. (2017). Implementing predictive learning analytics on a large scale: the teacher's perspective. In: Proceedings of the seventh international learning analytics \& knowledge conference, Vancouver. ACM, NY, 267-271.

Jisc. (2017). Learning analytics in higher education: a review of UK and international practice. Jisc. Retrieved from: https://www.jisc.ac.uk/reports/learning-analytics-in-higher-education

Jisc. (2018a) Effective learning analytics. Retrieved from: https://www.jisc.ac.uk/rd/projects/effective-learning-analytics

Jisc. (2018b). Horizon scanning. Jisc Project. Retrieved from: https://www.jisc.ac.uk/rd/projects/horizon-scanning

Kahneman, D. (2011). Thinking, fast and slow. New York: Farrar, Strauss and Giroux.

Ker, I. (2011) Newman's idea of a university and its relevance for the 21st century. Australian eJournal of Theology, 18, 19-32.

Lai, E., \& Viering, M. (2012). Assessing 21st century skills: Integrating research findings. National Council on Measurement in Education, Vancouver, Canada.

Learning Machine (2017). Learning Machine company. Retrieved from: https://www.learningmachine.com

Levy, D. (2018) Global private higher education: an empirical profile of its size and geographical shape. Higher Education. doi.org/10.1007/s10734-018-0233-6 
Li, F. (2015). Developing a credit recognition system for Chinese higher education institutions. Journal of Higher Education Policy and Management, 37, 424-431.

Lombardi, M. (2007). Authentic learning for the 21st century: an overview. ELI Paper 1 , EDUCAUSE. Retrieved from: https://library.educause.edu/resources/2007/1/authenticlearning-for-the-21st-century-an-overview

Long, P., \& Siemens, G. (2011). Penetrating the fog: analytics in learning and education. Educause Review, 46, 31-40.

Macdonald, K. (1995). The sociology of professions. London: Sage.

Mainelli, M. \& Smith, M. (2015). Sharing ledgers for sharing economies: an exploration of mutual distributed ledgers (aka blockchain technology). Journal of Financial Perspectives, 3, 2-44.

Manyika, J., Lund, S., Bughin, J., Robinson, K., Mischke, J. \& Mahajan, D. (2016). Independent work: choice, necessity, and the gig economy. McKinsey Global Institute. Retrieved from: https://www.mckinsey.com/featured-insights/employment-and-growth/independent-workchoice-necessity-and-the-gig-economy

Manyika, J. (2017). Technology, jobs, and the future of work. Executive briefing, McKinsey Global Institute. Retrieved from: https://www.mckinsey.com/featured-insights/employment-andgrowth/technology-jobs-and-the-future-of-work

McAfee, A. \& Brynjolfsson, E. (2017). Machine, platform, crowd: harnessing our digital future. London: W. W. Norton.

OBHE. (2018). Observatory on Borderless Higher Education. Retrieved from: http://www.obhe.ac.uk

Open Badges. (2016). Open Badges. Retrieved from: https://openbadges.org

Openblockchain. (2018). Researching the potential of blockchains. Knowledge Media Institute, The Open University, UK. Retrieved from: http://blockchain.open.ac.uk

OUA. (2018). OU Analyse. Knowledge Media Institute, The Open University, UK. Retrieved from: https://analyse.kmi.open.ac.uk

Pardo, A. \& Siemens, G. (2014). Ethical and privacy principles for learning analytics. British Journal of Educational Technology, 45, 438-450.

Poulfelt, F. \& Buono, A. (2017). Larry E. Greiner: actionable knowledge in action. In: D. Szabla, W. Pasmore, M. Barnes \& A. Gipson (eds.) The Palgrave handbook of organizational change Thinkers. Cham: Palgrave Macmillan.

Redecker, C. \& Johannessen, $\varnothing$. (2013). Changing assessment - towards a new assessment paradigm using ICT. European Journal of Education, 48, 79-96.

Remus, D. \& Levy, F. (2016). Can robots be lawyers? Computers, lawyers, and the practice of law, The rise of the machines: artificial intelligence and the future of law, ABA Law Practice Division. Retrieved from: https://pdfs.semanticscholar.org/3162/e236746a99626a4e2a39b3e1b4a006797203.pdf

Schön, D. (1983). The reflective practitioner: how professionals think in action. New York: Basic Books.

SGE. (2017). Creating a trusted experience with blockchain. Sony Global Education, Inc. Retrieved from: https://blockchain.sonyged.com

Scheuer O. \& McLaren B. (2012). Educational data mining. In Seel N. (ed.) Encyclopedia of the sciences of learning. Boston, MA: Springer.

Schumpeter, J. (1994). [1942] Capitalism, socialism and democracy. London: Routledge.

Seely Brown, J. (2012). Learning in and for the 21st century. C. J. Koh professorial lecture series number 4, National Institute of Education, Singapore. Retrieved from: http://www.johnseelybrown.com/CJKoh.pdf

Sherman, E. (2015). 5 white-collar jobs robots already have taken. Fortune, 25 February. Retrieved from: http://fortune.com/2015/02/25/5-jobs-that-robots-already-are-taking/

Slade, S. \& Prinsloo, P. (2013). Learning analytics: ethical issues and dilemmas. American Behavioral Scientist, 57, 1510-1529. 
SoLAR. (2018). Society for learning analytics research. Retrieved from: https://solaresearch.org

Stavredes, T. (2005). Just-in-time learning. In Encyclopedia of Distance Learning, (pp. 1162-1166). Hershey: ICI Global.

Stensaker, B. \& Maassen, P. (2015). A conceptualisation of available trust-building mechanisms for international quality assurance of higher education. Journal of Higher Education Policy and Management, 37, 130-40.

Sturgis, C. (2016). Reaching the tipping point: insights on advancing competency education in New England. A Competency Works report. Retrieved from:

https://www.competencyworks.org/wpcontent/uploads/2016/09/CompetencyWorks Reaching-the-Tipping-Point.pdf

Tam, M. (2014). Outcomes-based approach to quality assessment and curriculum improvement in higher education. Quality Assurance in Education, 22, 158-168.

Tempelaar, D., Rienties, B., \& Giesbers, B. (2015). In search for the most Informative data for feedback generation: learning analytics in a data-rich context. Computers in Human Behavior, 47, 157-167.

Thomas, D. \& Seely Brown, J. (2011). A new culture of learning: cultivating the imagination for a world of constant change. Douglas Thomas and John Seely Brown. Retrieved from: http://www.newcultureoflearning.com

University learning store. (2018). University learning store catalog. Retrieved from: http://universitylearningstore.org/course/

UQ 2018). UQ guide 2018. University of Queensland. Retrieved from: https://uq.edu.au/student/uq-guides/UGA-UQ-Guide-2018.pdf

University of Sydney. (2017). 6 jobs you've probably never heard of. University of Sydney. Retrieved from:

https://sydney.edu.au/campus-life/student-news/2017/07/28/6-jobs-youve-probably-neverheard-of.html

University of Sydney. (2018). The Sydney undergraduate experience. University of Sydney. Retrieved from: https://sydney.edu.au/study/find-a-course/undergraduate-courses.html

Voogt, J. \& Roblin, N. (2010). 21st Century skills. Discussion paper. University of Twente, Netherlands. Retrieved from: http://opite.pbworks.com/w/file/fetch/61995295/White\%20Paper\%2021stCS Final ENG def 2.pdf

Watters, A. (2016). The blockchain for education: an introduction. Hack Education. Retrieved from: http://hackeducation.com/2016/04/07/blockchain-education-guide

WGU. (2018). Competency-based education at Western Governors University. Retrieved from: https://www.wgu.edu/about/competency-based-education.html\#close

Williams, P. (2014a). Rethinking university assessment. International Journal of Technology and Inclusive Education, 3, 257-264.

Williams, P. (2016). Assessing collaborative learning: big data, analytics and university futures. Assessment \& Evaluation in Higher Education, 42, 978-989.

Woolf. (2018). Woolf - Building the First Blockchain University. Retrieved from: https://woolf.university/\#/ 